\title{
The Evaluation of Treatment Services and Systems for Substance Use Disorders ${ }^{1,2}$
}

\author{
Dr. Brian Rush, Ph.D.*
}

\section{NEED FOR EVALUATION}

Large numbers of people suffer from substance use disorders ${ }_{1}$ and require treatment. Despite primary prevention and efforts to control the supply of alcohol and other drugs in the communities around the world, the number of

Health Systems Research and Consulting Unit Centre for Addiction and Mental Health Toronto, Ontario

* Dr. Rush is a Senior Scientist with the Centre for Addiction and Mental Health in Toronto Canada and Associate professor in the Dept. of Psychiatry at the University of Toronto. He is recognized as an international expert in the field of addiction and mental health services research, with particular expertise in the evaluation of programs and service delivery systems.

Acknowledgement: The author would like to acknowledge the contributions of Dr. Alan Ogborne, formerly with the Addiction Research Foundation of Ontario and Dr. Maristela Monteiro of the World Health Organization, Substance Abuse Department. An earlier version of this article was published as part of a series of workbooks on the evaluation of treatment programmes for substance use disorders. The figures and charts are reproduced here with the permission of WHO. A Portuguese version of the text is published in Portugal.

1 There are many terms used for 'problems' related to alcohol and drug use (e.g., drug addiction, alcoholism, dependence, abuse, misuse). We will use the more general term psychoactive substance use disorders to reflect the international standard of DSM IV, thus encompassing alcohol or other drug dependence and abuse. We will also use the term substance use problems in a synonymous fashion."

${ }^{2}$ A treatment "system" can also refer to a collection of integrated services under one larger organization or administration. people entering treatment continues to grow. In broad terms, treatment is provided with the hope of improving the health and quality of an individual's life. Health, as defined by the World Health Organization (WHO), is not only the absence of disease but the presence of physical, mental and social well-being. Given the broad scope of outcomes to be achieved, treatment is delivered through many different types of organizations and therapeutic approaches.

Scientific research and programme evaluation have not played a major role in shaping the development of treatment services and systems in most countries. Treatment services are traditionally planned and funded on an individual basis. Programme planners and decision-makers have relied more on personal experience and opinions than on evaluation data that is systematically gathered and analyzed. This has led to disparities in the development and management of national and international treatment services and systems. The needs of the overall population often are not met as a result of inefficient use of scarce resources.

Recebido em 23/10/2003. Revisado em 28/10/2003. Aprovado em 04/11/2003. 
There is good evidence from well-controlled scientific studies that treatment for substance use disorders can result in good outcomes ${ }^{1,2}$. However, most of the commonly used treatment approaches either have not been evaluated, or continue to be used despite little research evidence on their effectiveness. Costeffectiveness analyses are rare. Reforms in the structure of health and

social care systems underway in many nations, and scarcity of resources available for treatment of substance use disorders, demand that the role of research and programme evaluation become more prominent than in the past. Evaluation findings that show positive benefits of treatment also need to be better communicated to the community and policy makers. The development of rational policies related to service provision is best achieved by systematically assessing the needs and evaluating the costs and outcomes of various treatment approaches. Although there are many challenges to conducting field research and programme evaluation in this area, these questions related to cost and effectiveness can be investigated.

This article aims to educate programme planners, managers and key decision makers about the importance of programme evaluation and its role in planning and delivering substance abuse treatment services and systems. In fulfilling this objective we hope to reduce barriers in conducting programme evaluations and using the results in the decision-making and resource allocation process.

\section{WHAT IS TREATMENT?}

Since the intent of this report is to promote quality evaluation practices within alcohol and other drug treatment programmes, it is helpful to start with a common view of what comprises "treatment". The term treatment is used to define the process that begins when psychoactive substance users come into contact with a health provider or other community service, and may continue through a succession of specific interventions until the highest attainable level of health and well-being is reached. Treatment and rehabilitation are defined as a comprehensive approach to detection, assistance, health care, and social integration of persons presenting problems caused by any psychoactive substance use.

"Treatment" can also be defined in relation to the term "prevention", with the former aimed alcohol and other drug use, and the latter intended to prevent their occurrence in the first place. It is sometimes debated as to whether "brief interventions" are considered treatment since they have objectives typically associated with secondary prevention. These objectives include identifying and advising people who are just beginning to experience problems, or who are at elevated risk of such problems due to the amount and pattern of their alcohol and other drug consumption ${ }^{3}$. For the purpose of this article brief interventions are included within the definition of treatment.

Since there is a diverse range of treatment methods for substance use disorders, many different approaches need to be evaluated. Indeed, the diversity is so great that this has inhibited the development of an international classification system of treatment approaches ${ }^{4}$. It is important to give some structure to the description of treatment, however, as this will facilitate the development of evaluations that compare different approaches, and encourage the sharing of information from evaluations conducted in different parts of the world.

A report by the World Health Organization ${ }^{4}$ outlines various dimensions of treatment. These dimensions include modality, setting, principles, stage, and target population.

Modality: Treatment modalities refer to the specific activities that are intended to build upon a person's strengths, facilitate behavior change and improve problem areas. In short, it is the content of treatment. There are five broad types of modalities - bio-physical, pharmacological, psychological, sociocultural, and mixed modalities that combine more than a single type.

Setting: A setting is the location or organizational, administrative context in which treatment for substance use disorders occurs. Some treatment settings specialize in serving people with alcohol and other drug problems and these are often further subcategorized (e.g., detoxification centres, hospital inpatient facilities, community residential programmes such as therapeutic communities, assessment and referral centers, outpatient programmes). Other treatment settings are generalist in nature, and thus do not specialize in substance use disorders. They may include services devoted to health care and other settings such as criminal justice, workplace, religious and educational services.

Principles: The principles underlying treatment reflect the views of the people who manage and operate the programme and their 
belief in the underlying cause of substance use disorders. Principles include moral, spiritual/ existential, biological, psychological, sociocultural and integrative models.

Stage: Treatment can be divided into stages, with some types of treatment activities fitting more comfortably into one stage or another. There are three primary stages of treatment - acute, active and maintenance and each of these stages can be further subdivided.

Target Groups: Not all treatment activities or settings are intended to deal with the same types of people or substance use disorders. Treatment targets may differ according to the substance used; concomitant co-morbidity (e.g. people with certain types of concurrent mental disorders); the unit of interaction with which the therapist deals (e.g., individual, couple, group, social network), and the characteristics of the individual or interactive unit (e.g., gender, age).

\section{LEVELS OF EVALUATION}

In the evaluation of treatment for substance use disorders, the evaluation practitioner will usually be working at one of the following five levels:

- single case

- treatment activity

- treatment service

- treatment agency

- treatment system

Single case evaluation is consistent with clinical practice in that it promotes a problemsolving approach to planning, implementing and evaluating interventions tailored specifically for each client ${ }^{5}$. Responsibility for getting feedback on the progress of each client typically rests with the clinician or therapist.

The evaluation of a treatment activity involves summarizing the participation of a group of clients with a particular treatment modality (e.g., cognitive-behavioural therapy; specific pharmacotherapy; opiod replacement), and the progress they have made collectively toward reaching their objectives. One approach called 'goal-attainment scaling' measures the progress of each client toward their individual objectives $^{6}$, and summarizes the information on a common scale. A more widely accepted approach is to identify objectives shared by all clients participating in the treatment activity, and to use these shared objectives to assess the progress of the overall group.

The evaluation of a treatment service also involves summarizing information about a group of clients. One treatment service (e.g., outpatient) can include more than one treatment activity or modality (e.g., cognitive-behavioural therapy, relapse prevention, social skills training). Since each client may be involved with many services, the ability to isolate the main factors contributing to changes in the individual, and the group as a whole, becomes more difficult than activity-level evaluation. The term "programme" is often used synonymously with the term treatment service.

A treatment agency may offer more than one type of treatment service (e.g., detoxification, inpatient, outpatient and continuing care). An evaluation at the agency level will summarize information about the involvement of a group of clients potentially receiving many services within the entire agency and their progress towards treatment objectives. Conclusions about the main factors contributing to positive change across the group become even more difficult to make at the agency level. The term "programme" is also sometimes used synonymously with the term agency.

A community treatment system is comprised of many different treatment activities, services and agencies ${ }^{3}$. It includes both specialized and generalist services and agencies. The term "network" is sometimes used synonymously with the treatment term system. Both the terms "network" and "system" imply a certain amount of coordination and working together toward common purposes. In most communities, however, there is little evidence of system - like, inter-organizational behaviour among substance abuse service providers. An evaluation at the system level can examine the involvement of clients with various agencies and services and monitor their progress toward a number of objectives. At the system level it its extremely difficult to attribute changes in client functioning to their involvement with any one element of the treatment network ${ }^{7}$. For evaluation at this level, however, it is also appropriate to examining changes in system functioning (e.g., penetration rate, decreased waiting periods, decreased drop-out rates after referral, improved coordination, sharing of resources, collaborative planning). Assumptions are then made that the improvements to system functioning will translate into improved (or at least equivalent) client outcomes, but with more efficient use of system-wide resources.

The following sections discuss the development of programme evaluation and 
describe different types of evaluation. The discipline of programme evaluation evolved primarily at the level of interventions (activities), services and agencies. Most of the material presented in this article reflects these levels and for the ease of presentation the term "programme" evaluation is often used. In each of the sections issues in the evaluation of treatment systems are also considered, while recognizing that our experience in this area is in the early stages. This is especially true with respect to measures of system integration and efficiency. However, the basic principles and practices of quality evaluation apply equally well to all levels of treatment activity, services, agency and systems (for an example of a system-level evaluation in the mental health (field) $)^{8,9}$.

\section{EVALUATION AS FEEDBACK}

The discipline of programme evaluation traces many of its roots to the broader fields of medicine, public health, education, sociology, and industrial psychology. The application of social science methodologies during the two world wars (e.g., for screening and training army inductees) was particularly important in furthering understanding of evaluation and the development of methods. Following WWII, developments in market and survey research, and the advent of computer-based analyses using large amounts of data, helped to define the nature and scope of programme evaluation. In the United States, for example, the post-war economic boom financed many comprehensive social programmes and introduced programme and policy evaluation on a wide scale.

In the 1960's and 1970's, the prevailing view of evaluation was that health and social programmes provided the opportunity to apply rigorous scientific designs and measurement principles from the health and social sciences to test new ideas and new programmes. This perspective is reflected, for example, in a definition of programme evaluation offered in one of the classic and early textbooks on evaluation:

"evaluation research is the systematic application of social science research procedures in assessing the conceptualization and design, implementation and utility of social intervention programmes"10
1980 's wherein evaluation was thought of not so much as a strictly scientific enterprise (although it retained strong elements of this tradition), but as one of several tools for the management of health and social programmes. Evaluation became commonly viewed in the context of quality improvement ${ }^{11}$ or organizational learning $\frac{12}{}$, and more likely to be financed and implemented with resources internal versus external to the programme ${ }^{13}$. Today, its purpose is more clearly tied to ongoing programme accountability or enhancement rather than giving the program a one-time pass/fail grade. The following definition of evaluation reflects this shift in thinking:

$$
\begin{aligned}
& \text { "programme evaluation entails } \\
& \text { systematically gathering, analyzing and } \\
& \text { reporting information about a programme, } \\
& \text { service or intervention, for use in making } \\
& \text { decisions". }{ }^{4}
\end{aligned}
$$

A major goal of researchers and evaluation consultants working within an internal evaluation context is to develop the program's own capacity for undertaking evaluation activities and using the results for making decisions. Some seek to accomplish this by grounding the evaluation in the practices and principles of participatory action research ${ }^{15,16}$. Another development has been the growth of "performance measurement systems" which use quantitative indicators to assess the achievement of a sub-set of program objectives ${ }^{17,18}$. Performance measurement typically focuses on a small number of agreed upon performance indicators which are often reported in a "score card" format ${ }^{19}$. In recent years there have also been profound changes in the strategies by which the effectiveness of health and mental health services is evaluated. Mental health services research that develops new knowledge with broad application and generalizability now includes a wide variety of qualitative and quantitative methods to complement more traditional randomised controlled trials ${ }^{7,20}$.

For many people thinking about or getting involved in programme evaluation for the first time they often think of "evaluation" and "research" as being the same thing. Although they share much in common because of programme evaluation's historical roots, there are important, often subtle, distinctions. For example, the questions addressed in research are more likely to be based on theoretical 
issues; the goal is likely to generalize the results to other contexts; and the resources for the evaluation are more likely to come from outside the programme. With respect to programme evaluation, the questions addressed are more likely to be based on the needs of the treatment service or system, the priority is to provide important feedback to the specific service or system in question; and resources for the evaluation are more likely to be found internally rather that externally. These are not hard and fast rules but they do help make this important distinction.

One of the major barriers to undertaking internal programme evaluation is the belief that it is a complicated research process best left to those with specific research training. Programme managers and staff can plan and initiate an evaluation process for their programme if they have access to research expertise when needed for certain parts of the process. There are times when one requires complicated strategies to ascertain some aspects of programme effectiveness, and the traditional scientific methods may be needed. This is especially true in outcome evaluation where it is important to try to attribute the changes you have measured in clients to the programme that has been delivered. There are other times, however, when feedback in less complicated, for example, in developing a system of documentation to record whether the people using your programme match those you intended to serve.

\section{PROGRAMME EVALUATION AND CONTINUOUS QUALITY IMPROVEMENT}

A major trend in the field of health care administration during the 1990's has been the introduction of continuous quality improvement processes (CQI) to ongoing programme planning and management. CQI represents a general philosophy in programme administration. Many of the principles and techniques involved are closely related to internal, action-oriented programme evaluation. Within health care settings, including substance abuse services and systems, programme evaluation can be viewed as an essential component of a broader CQI process.

In CQI there is an intense focus on customer satisfaction, accurate measurement of activities, ongoing improvement of services and operational processes, and meaningful involvement of people at all levels in the organizational process ${ }^{11}$. These ingredients, together with techniques such as programme logic models, process flow charts, client satisfaction surveys and routine outcome monitoring, are closely related to programme evaluation.

\section{PROGRAMME MONITORING VERSUS PROJECT EVALUATION}

It is also useful to distinguish between the on-going monitoring of a treatment service or system and the planning and implementation of a time-limited project. Service or system-level monitoring will assess selected aspects of the treatment process, for example, levels of activity, involvement of different types of clients and interaction between services. Treatment outcomes (such as reduced drug use and improvement in physical and mental health) will also be monitored on a continuous basis. Such monitoring systems are now typically operated as computerized information systems ${ }^{21}$. The planning of such monitoring systems involves careful attention to:

- the information needs of key decisionmakers

- identification of key questions and issues that require the collection of information on an ongoing basis

- the cost of data collection and analysis relative to the benefits of routine information on programme or system operations and effectiveness

- the nature and extent of participation in the monitoring system and quality of the data being gathered.

Sometimes it is desirable to get feedback about a programme, or network of programmes, through a one-time evaluation project that has specific objectives and a time-frame for completion and reporting of the results. Such projects typically go through the following phases, with distinct tasks to be accomplished at each phase ${ }^{14}$ :

- evaluation planning

- conducting the study and reporting the findings

- decision-making and implementation 
Table 1. Steps in Conducting a Programme Evaluation

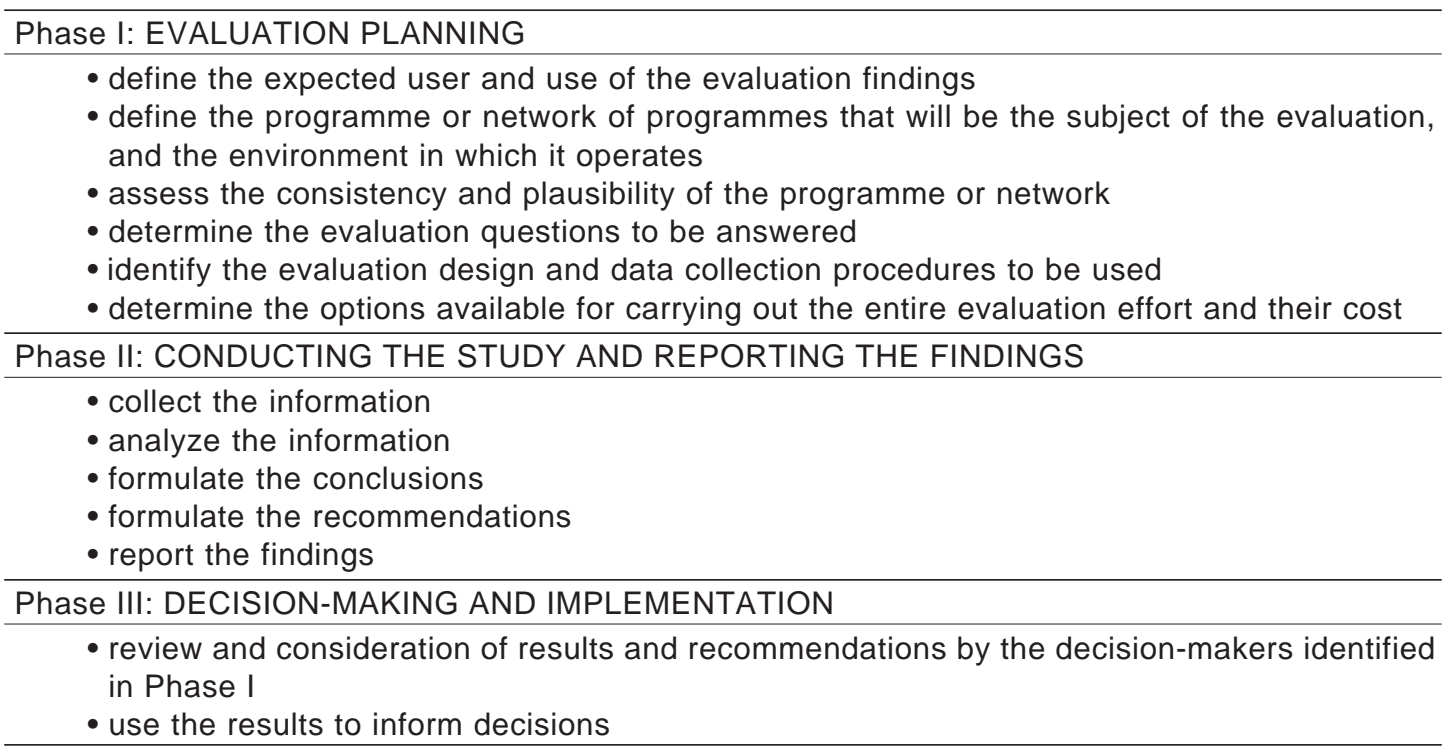

\section{A FRAMEWORK FOR EVALUATION}

Figure 1 shows the seven main components of an evaluation process that can be planned and implemented for a treatment activity, service, agency or system:

- need assessment

- evaluation planning

- process evaluation

- cost analysis

- client satisfaction evaluation

- outcome evaluation

- economic evaluation

The components are presented in a stepped model to illustrate the often sequential nature of some evaluation activities. This does not imply, however, that one type of evaluation is "better" than another. The need assessment phase typically precedes programme development and setting of programme objectives and operational details. Specific evaluation questions, issues and data collection processes are developed during the evaluation planning stage. Process evaluation and cost analysis typically precede the assessment of outcomes and costeffectiveness, in order that the outcomes and key components can be properly explained. Cost-effectiveness studies should be conducted after there is at least some preliminary evidence of programme effectiveness.

Figure 1. A Stepped Model of Treatment Service or System Evaluation

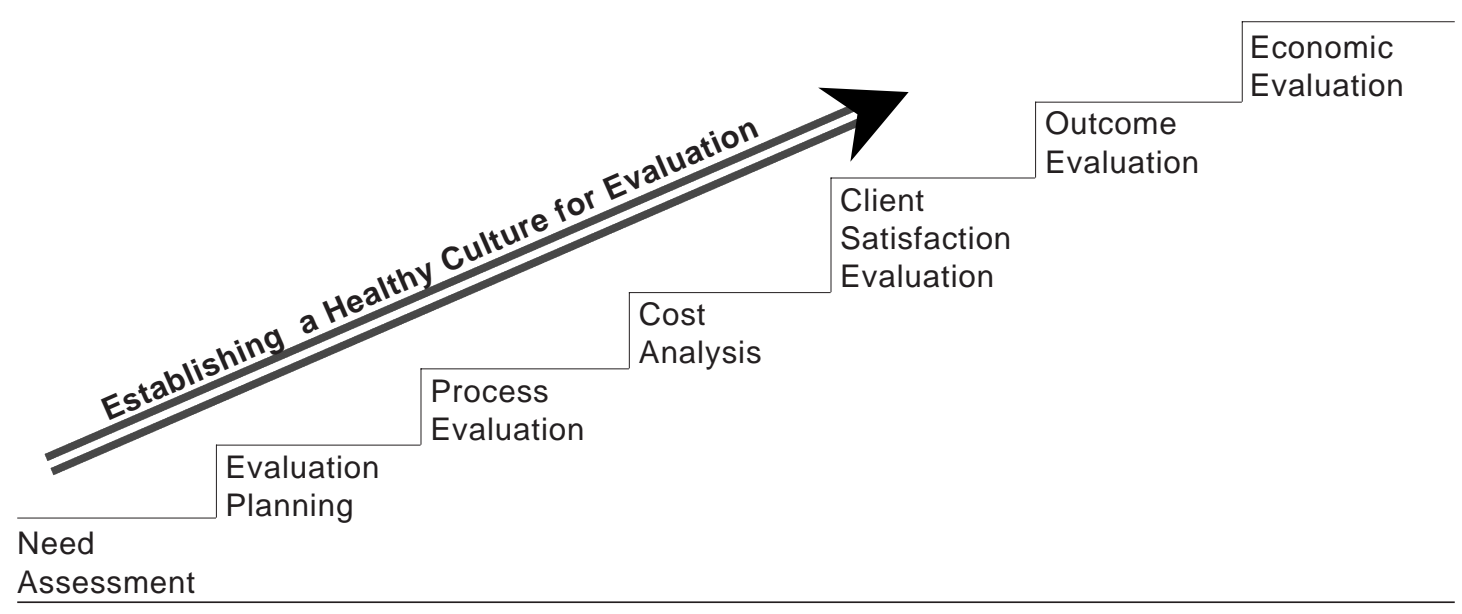




\section{NEED ASSESSMENT}

Need assessment is the first category of programme evaluation. Ideally, it should take place before the programme, or the network of programmes, is planned and implemented. A need assessment can, however, also address questions about how an existing programme or community network of programmes should be re-designed to address needs that are not being met. The following are some of the questions asked in need assessments:

- What type of treatment interventions should the programme provide?

- How many people should be anticipated each year in our services?

- What is the prevalence and incidence of specific psychoactive substance use disorders in the community?

-What are the main gaps in the community treatment system?

- What is the projected demand for treatment in the community or the region as a whole?

Need assessment is a formal and systematic attempt to determine, and then address, gaps between "what is" and "what should be". It involves documenting important discrepancies between current outcomes and desired outcomes and prioritizing these discrepancies for program planning and intervention in order to close that gap. In this way, need assessment involves both need identification and need prioritization. The first stage typically involves a comparison of the existing state of affairs with some standard or "ideal" state of affairs, for example, comparing current treatment capacity with an estimate of required capacity. The standard or ideal situation may be based primarily on perceived needs or wants as advocated by members of the general public or professionals. It is preferable, however, to define the ideal situation on the basis of research and best practices.

Some need assessments focus on the prevalence and incidence of substance use disorders in the community. This may be done without any assumptions about a particular organization's role or mandate and, therefore, no preconceived notions about solutions to close gaps in service. In other circumstances, the need assessment is specific to a particular service, or network of services. It assumes the perspective of the existing service(s) and seeks to demonstrate the need for new or modified approaches to service delivery. Most need assessments combine some elements of both approaches, for example, focusing on problems in the community related to substance use and the adequacy of existing resources to meet the challenges posed by these problems.

It is also helpful to draw a distinction between need assessment models and need assessment methods ${ }^{22}$. A model is a conceptual tool used to help make sense of abstract phenomena in the real world. An example would be a prescriptive model of how people enter and move through a community network of services, to help assess the current capacity of the system $^{23}$. Dewit and Rush ${ }^{24}$ provide a critical review of need assessment models.

In contrast to need assessment models, a need assessment method refers to a particular approach to data collection, for example, a population survey, social indicator analysis or key informant survey. It is widely acknowledged that each method brings distinct advantages and disadvantages to assessing need and that a mixed or convergent approach provides a more reliable and valid assessment of need.

\section{EVALUATION PLANNING}

Since expectations of evaluation vary considerably it is important that time be set aside to carefully plan. This planning phase is sometimes referred to as evaluation assessment ${ }^{25,26}$. The following are some of the questions that might be asked when entering the evaluation planning phase:

-Who wants to evaluate the treatment service or system and why?

-Where should we invest our evaluation resources?

-What parts of our programme or system are the most important to get feedback on?

- From whose perspective will the evaluation be undertaken?

During the evaluation planning phase it is important to clarify the expectations of various stakeholders and their role in the evaluation process. It is also essential at this stage that the various groups involved come to a common understanding of the structure, rationale, and objectives underlying the programme or network of programmes. This is often achieved through the use of a logic model which shows the logical connections between programme activities to the outcomes to be achieved ${ }^{27}$ (27). Programme logic models are an important aspect of theorydriven evaluation (28) and services research (7, $20)$. They have also been used as an effective 
tool for program planning since they highlight the theory or rationale that links the planned services to community needs ${ }^{29,30}$. They are a common element of evaluation training guidebooks ${ }^{31,32}$, and a critical component of new measurement tools that assess the quality of performance measurement systems and program accountability processes ${ }^{33}$.

Logic models contain two types of objectives - process and outcome. Process objectives concern the services to be delivered to the target population. Outcome objectives reflect the changes that are anticipated as a result of delivering these services. The

Table 2. Examples of Process and Outcome Objectives

Process Objectives

- to assess clients in individual and group sessions to obtain basic screening information

- to provide eight, weekly continuing care sessions for clients completing the programme

- to conduct comprehensive psychiatric assessment for co-morbidity

Outcome Objectives

- to increase the client's ability to identify and anticipate situations that put them at high risk for

substance use

- to reduce alcohol and other drug use

- to increase social and psychological well-being

Figure 2. Programme Logic Model for Inpatient Opiate Detoxification Service

\section{Main Components}

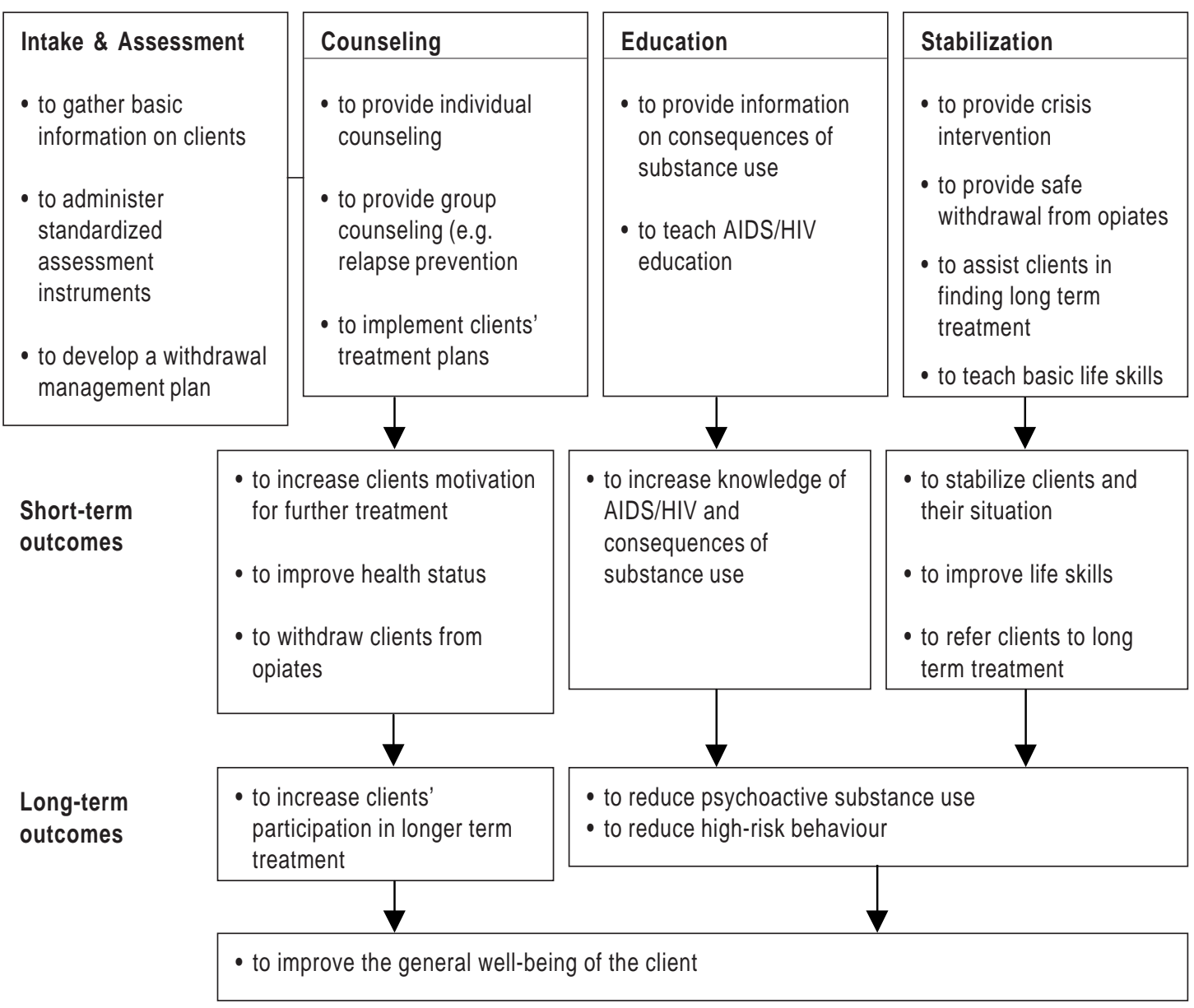


programme logic model focuses on the logic or rationale that links the services with a sequence of outcome objectives. Table 2 gives some examples of the two types of objectives. Outcomes are usually ordered in a sequence of short-term and long-term objectives. Since evaluations often ask about the extent to which objectives have been met, considerable attention is paid to how clearly they are stated and how measurable they are.

Since a logic model gives a relatively "static" representation of programme activities it is often supplemented with a process flow chart in the evaluation planning phase. A process flow chart provides a visual representation of the process objectives identified in the logic model. It depicts each step in the process of service delivery, for example, handling inquiry contacts, collecting basic intake information, assessing client strengths and problem areas, and developing treatment plans. The anticipated time within and between each step is also noted.

Logic models and flow charts help to understand the treatment service and what is required to achieve the desired outcome. Routine information systems should be in place to gather information relating to unacceptable variability at critical points in the treatment process (e.g. waiting periods). Information systems provide important data for the evaluation. In many instances the development of a logic model and process flow chart will show the need for an improved information system to provide such feedback on an ongoing basis.

In addition to clarifying the theory and abstract reasoning that links programme activities with outcomes, the evaluation planning phase is undertaken to determine underlying programme principles. Clarification of these principles eases the task of selecting appropriate outcome measures. For example, an evaluation of a programme based on a harm reduction philosophy would probably focus on a wider range of outcomes related to alcohol and drug use, that a programme based on an abstinence philosophy.

Knowledge of the expectations and value systems of various stakeholders, coupled with a systematic review of the programme logic model and process flow chart, greatly facilitates the identification of key questions and issues that should be addressed in the evaluation. In this planning phase, evaluation questions are prioritized, followed by the specification of measures, indicators and data collection strategies to address the questions. Table 3 gives an example of an evaluation framework. The evaluation planning phase culminates with a clear statement of the components of the programme or system to be evaluated, the questions to be addressed, and the specific data collection strategies, measures and analyses to be employed. It includes a workplan for the evaluation and gives a clear indication of how the resulting information will be used.

Table 3. Basic Format for Moving from Logic Model to More Detailed Evaluation Planning

\begin{tabular}{|c|c|c|c|}
\hline $\begin{array}{l}\text { Program Objective } \\
\text { (from the logic model) }\end{array}$ & Evaluation Questions & $\begin{array}{l}\text { Outputs, Measures, } \\
\text { Indicators }\end{array}$ & $\begin{array}{l}\text { Data Collection } \\
\text { Strategy }\end{array}$ \\
\hline
\end{tabular}

\begin{tabular}{|c|c|c|c|}
\hline $\begin{array}{l}\text { Objective } 1 \\
\text { - to develop a } \\
\text { withdrawal } \\
\text { management plan }\end{array}$ & $\begin{array}{l}\text { Did all clients have a } \\
\text { plan documented? } \\
\text { Did the plan include } \\
\text { appropriate supervision? }\end{array}$ & $\begin{array}{l}\text { - case notes showing } \\
\text { plan and supervision } \\
\text { levels }\end{array}$ & $\begin{array}{l}\text { - review and coding of } \\
\text { case notes }\end{array}$ \\
\hline $\begin{array}{l}\text { Objective } 2 \\
\text { - to provide group } \\
\text { counseling (e.g. } \\
\text { relapse prevention) }\end{array}$ & $\begin{array}{l}\text { Did all clients complete } \\
\text { the relapse prevention } \\
\text { component? }\end{array}$ & $\begin{array}{l}\text { - drop-out rate } \\
\text { - average number of } \\
\text { sessions completed }\end{array}$ & - routine documentation \\
\hline $\begin{array}{l}\text { Objective } 3 \\
\text { - to increase clients' } \\
\text { participation in } \\
\text { treatment }\end{array}$ & $\begin{array}{l}\text { Has the program been } \\
\text { successful in linking } \\
\text { people with more } \\
\text { intensive treatment? }\end{array}$ & $\begin{array}{l}\text { - percent of clients } \\
\text { engaged in treatment } \\
\text { three months } \\
\text { post-discharge }\end{array}$ & $\begin{array}{l}\text { - follow-up of a } \\
\text { random sample } \\
\text { of clients } \\
\text { - treatment admission } \\
\text { data from community } \\
\text { agencies }\end{array}$ \\
\hline
\end{tabular}


A written evaluation plan is important since it documents what will be done, why it is being done, by whom and at what cost. This will help keep things on track and facilitate accountability for the evaluation process itself. A written evaluation plan often has the following sections:

- Background (What led up to the need for evaluation?)

- Stakeholder involvement (How are they represented and involved? Who wants to know what from the evaluation?)

- Programme logic model (Rationale and objectives)

- Evaluation framework (Potential and prioritized questions; data collection and analysis plan)

- Reporting and using the results (Who will the results be reported to and by whom? How will the results be used?)

- Costs (What will it cost to implement the evaluation? What would different options cost?

\section{PROCESS EVALUATION}

The basic purpose of process evaluation is to describe what is going on in the programme and the context in which it is operating. These are the types of questions that are addressed in process evaluation:

- How many clients are treated each year?

- Is the type of client(s) being seen the same as for whom the programme or treatment system has been designed?

- Are people experiencing difficulty accessing the programme? How long is the waiting list and how are people being managed while they wait?

- Are the staff conducting client assessments, or providing treatment, appropriately trained and using "state-of-theart" methods?

At this stage, the evaluation questions do not ask about changes in clients that result from services being provided. Rather the questions concern coverage (i.e., is the programme or system reaching all those for whom it was intended; process (i.e., has the programme or system been implemented as intended and in an integrated manner?); and quality (i.e. is the programme or system being delivered in a manner consistent with professional standards and acknowledged best practice?).

Planning a process evaluation involves setting out expectations of what should happen in the programme or treatment system. Logic models and process flow charts are invaluable tools in developing these specifications. If these tools were not employed in the evaluation planning phase, they should be employed in the process evaluation to assist in programme or system description. The evaluation then seeks to determine the extent to which the programme is operating as reflected in the logic model and flow charts.

The strategies and sources of information that are applied to process evaluation will depend on the circumstances of each programme or system being evaluated. Some strategies are more appropriate at the programme level than at the system level. The following approaches may be used in process evaluation:

- review of services (either written or computerized) that monitor the characteristics of people being treated, the services they receive, and the pathways people follow within and across these services;

- documentation of services received and their relationship to the client's treatment needs, for example with an instrument such as the Addiction Services Review ${ }^{34}$;

- an assessment of the coordination of services within a service or across the treatment system;

- focus groups or interviews with service participants or others such as community planners, managers, staff, community agency representatives and families;

- observation of the service(s) in action, for example, to rate the extent and quality of implementation and integration with other programmes;

- surveys of the population for whom the service or treatment system was intended and of actual service participants. Such surveys might be done, for example, to determine the proportion of people in need who are being served and to compare people being treated with those who are not;

- follow-up surveys or interviews with people who have dropped out of the service prematurely to determine the reasons why.

\section{COSTING EVALUATION}

The broad aim of costing studies is to trace the resources used under different circumstances. Questions which could be addressed include:

-What is the social cost or economic burden of substance use disorders?

- If alternative treatment approaches are producing equivalent outcomes, how do these 
approaches compare in cost?

- What are the different costs involved in the delivery of a service or service delivery system?

- How do changes in costs relate to activity levels?

Answering these types of questions will involve different approaches to cost analysis.

Social cost studies trace the impact of a particular substance within a jurisdiction for a given period, usually a year. Information on the burden of a particular drug on society is used to guide policy action. The disadvantage of these studies is that they do not evaluate alternative policies which may reduce this burden. A Canadian study represents a good example of a social cost study ${ }^{35}$ and there have been attempts to standardize underlying assumptions and methodology on an international basis ${ }^{36}$.

Cost minimization studies calculate and compare the resources being used to deliver different treatment activities or services. Where outcomes are equivalent, it may be suggested that the treatment requiring the least resources be considered for continuation. Interestingly, in most cost minimization studies only direct resources in delivering care are compared. Persons with substance use disorders tend, however, to use more health and social services than other people with similar demographic characteristics. One should, therefore, consider the expected use of resources across a wide range of community services and not just within one's own programme.

Resource tracing studies examine the cost of the resources required to deliver various treatments per unit of service delivery (e.g., a one-hour counseling session, one inpatient day, one day of a methadone maintenance programme). There has been significant progress in recent years in the development of costing methodology for substance abuse services ${ }^{37,38}$, and there are now several examples of cost analyses in the research literature ${ }^{39,40,41}$. The information from resource tracing studies can be used by service providers to monitor how the resources within a treatment delivery programme are being used to deliver services. Different types of costs are distinguished to reflect cost variation as a result of changes in levels of programme activity: fixed costs (e.g., capital costs of facility space), semifixed costs (e.g., salaries for therapists), variable costs (e.g., cost of prescriptions, medical supplies, or food). It is important to know what resources are in which category in order to determine the relationship between total costs and the level of activity. The average cost for each "unit" of activity can vary depending on the activity level. It is important to know the point where, for example, increasing the level of activity results in a large increase in costs because of the need for additional fixed or semifixed components.

When an agency is delivering a single, structured programme, general resource tracing and calculation of the variations in cost per client may be all that is required in a cost analysis. Most programmes offer a range of interventions in different combinations for different types of clients. In such cases, it is desirable to calculate costs for each type of treatment activity provided. This process requires that different costs be attributed to different activities. The method of allocating costs to different activities will depend on internal mechanisms for monitoring staff time and other resources.

\section{CLIENT SATISFACTION}

Measuring clients' satisfaction with treatment received can provide a programme or treatment system with valuable feedback about the extent to which treatment activities have met with client expectations. The following are some of the questions that might be asked through a client satisfaction evaluation:

- Have the services received met the client's expressed needs?

- Are there aspects of the services that clients think could be improved?

-What is the perceived quality of care from the client's perspective?

Client satisfaction questionnaires are available for general use and are appropriate for alcohol and drug treatment programs. Although some are brief, user-friendly and have demonstrated reliability and validity ${ }^{42,43}$, the cross-cultural applicability is unknown in some instances.

In contrast to published instruments, other client satisfaction questionnaires can be developed to meet specific needs of service providers. Measures of client satisfaction to assess different elements of a programme, as opposed to the programme as a whole, are most helpful where information is needed to make improvements to service delivery. Measures can help determine client satisfaction with treatment activities, comprehensiveness of treatment, continuity of treatment, staff 
performance, and characteristics of the treatment environment. Measurement of client satisfaction along these dimensions should be a routine component of a continuous quality improvement process.

Leebow and Scott ${ }^{44}$ identified three aspects of client satisfaction that should be measured as part of a continuous quality improvement process. The first is the client's overall satisfaction with the programme and its general features. Next, measures are included which identify the attributes of the treatment process important to the client (e.g., timeliness; flexibility of treatment scheduling) important to the client. Finally, other measures ask whether the services provided in the programme met these expectations.

It should be stated that there are several limitations associated with assessing client satisfaction ${ }^{45}$. Firstly, measures of satisfaction with the overall programme may not allow clients to respond in an insightful way about specific activities that were perceived as unhelpful. Secondly, asking only about treatment that has been received may exclude the opportunity for clients to provide feedback on problems for which intervention was not provided. Finally, the timing of a client satisfaction survey is critical. If clients are asked about their satisfaction in the early stages of treatment they may feel their experience has been too limited to form an opinion. Alternatively, assessing client satisfaction toward the end of a lengthy treatment experience may produce an overly positive group response. This is because many dissatisfied clients will have left treatment by that time.

While client satisfaction surveys are an important part of a programme or system-level continuous quality improvement process, it is important to be cautious in interpreting the results. Client satisfaction can complement but not substitute for measuring outcomes that have been achieved by the various treatment activities and services.

\section{OUTCOME EVALUATION}

An evaluation of treatment outcome needs to accomplish two things: first, it must measure how clients and their circumstances have changed; and secondly it must show that the treatment experience has been a factor in causing this change. The following are some of the questions that might be asked in an outcome evaluation: aspects of the person's life affected by their substance use?

- Has there been a reduction in the frequency and/or quantity of substance use?

- Has there been a sustained period of abstinence or not-problematic use following treatment?

- Is treatment more or less effective for some types of clients?

- What is the relationship between programme or system participation and client improvement?

Design: There are a number of ways to design an outcome evaluation that will measure change and show that it is attributable to participation in the program. The most widely praised strategy to measure change, and infer causality, is a true experiment. This is sometimes called a randomized controlled trial since clients are randomly assigned to receive one or more treatment options (e.g., inpatient versus community detoxification; drug therapy or psychological therapy; brief versus longer intervention). Randomized controlled trials are considered the "gold standard" in the evaluation of treatment effectiveness. This is because the design allows for inference of causality; that is to say, changes may be attributed to the treatment examined rather than other extraneous factors.

Another strategy that is relatively strong in its ability to allow causal inference in the "quasiexperimental" approach. Rather than randomly assigning clients to different alternatives, the individuals are selected in a systematic way. Clients that receive two different treatment services, or participate in two different agencies or systems, are compared after undergoing treatment (e.g., therapeutic community versus methadone maintenance therapy for opioid dependence). In this design, the ability to make strong inferences of causality is improved if similar people are in the two conditions (i.e. a matched design). Statistical procedures can be used to adjust for differences across the groups before treatment begins. If such matching or statistical adjustment is not done it is possible that any differences which favour one group were due to differences that were present prior to treatment (e.g., differences in motivation or severity of the problem). Nonetheless, a twogroup comparison without matching or adjustment is more useful in determining the relative effectiveness of treatment than only measuring change in one group of clients.

Other types of non-experimental outcome 
studies examine changes for one group of clients over time and although not so powerful can still provide useful information. Clients are monitored in terms of changes before, and after treatment, and speculation is possible about the role of treatment in producing these changes. This is especially true if data are available for several points in time and a dramatic change occurs immediately after treatment is delivered.

The weakest method of measuring change and determining causation involves assessing one group of clients only after their treatment is completed. Although clinicians may have faith that clients have improved because of treatment, it is impossible to make statements about the extent of change and whether change occurred as a result of participation in treatment. This is because there is no measure of pretreatment behaviour or problems and not group to compare their progress to.

Measures: Whatever evaluation design is selected, the issue remains as to what outcomes will be measured and how they will be measured. In thinking about the outcomes to be measured it is important to distinguish between the "variables" you are interested in measuring (e.g. drug use, social support, psychiatric comorbidity); the "indicators" or the specific ways in which you will measure them (e.g. quantity and frequency of drugs used in the past 90 days; 10-item social support scale; DSM-IV diagnosis); and the "data" or actual observations you make. The variables to be measured and their indicators should have a direct relationship to the nature of the treatment provided, the treatment goals and important factors thought to influence achievement of these goals.

The measures or indicators should also be reliable and valid. Reliability means that the measures must be sensitive to change in a particular characteristic across time and this can be measured consistently. Validity refers to the measure's ability to accurately assess the characteristic of interest, for example, actual alcohol or drug use. There are many specific types of reliability and validity.

It is beyond the scope of this article to cover all the detailed and important issues in the selection and analysis of measures appropriate for outcome evaluation. This is a key aspect of the evaluation of substance abuse treatment that requires research expertise on your evaluation team or through a consultant. There are, however, excellent resource materials available which provide a lot of insight into the many measures available and important issues in their selection $20,31,46,47,48$.

Domains to be assessed: It is important to embed your outcome measures in the client assessment process in order to obtain your baseline data and avoid having the client complete two sets of instruments when they begin treatment ${ }^{49}$. A number of domains may be included for eventual examination of outcome. They are, among others: substance use frequency and pattern; consequences of substance use, including dependence; psychological functioning; physical health (including HIV); social adjustment; family functioning; crime and health care utilization. While it is not necessary to measure all domains when evaluating a treatment programme, one should examine more than one domain given the broad scope of treatment objectives. Another approach is to include a comprehensive measure of "quality of life" as an outcome measure. Considerable work has been undertaken to develop measures of quality of life which have broad application in different cultural contexts ${ }^{50}$.

A report by McLellan and colleagues ${ }^{51}$ provides advice on the most important domains to be assessed in outcome evaluation. Three broad outcome domains are recommended:

- reduction of alcohol and drug use

- improvement in personal and social functioning

- reduction in public health and safety threats

Methods: There are many methodological challenges in outcome evaluation and many guidelines for addressing them ${ }^{20,31}$. McLellan and colleagues ${ }^{51}$ recommend three minimum methodological criteria:

- an intention-to-treat analysis which selects a random sample of clients who are beginning the treatment process rather than a sample of clients who have completed treatment;

- independent evaluators not associated with the provision of the intervention to interview clients and collect the data. It is also advised that subjective reports of status after treatment be supplemented with breathalyzer, urine screening tests and/or collateral report to validate patient reports;

- a minimum of $70 \%$ contact for follow-up to ensure representative information from the treated sample

Systems Evaluation: Almost all of our 
experience with outcome evaluation has been with the evaluation of individual treatment activities and services. Recently, attention has been given to assessing outcomes associated with a network or "system" of treatment programmes.

System level outcome evaluation can involve any of the evaluation designs briefly described above (e.g., experimental, quasiexperimental, single-group pretest and posttest). It is typically impractical, however, to randomly assign clients to one network of services over another. The most practical design to implement is the pretest-posttest design with common baseline and outcome data collected from all programmes in the defined network. However, the ability to meet the minimal methodological criteria noted above depends on the resources available for systemwide outcome evaluation. Descriptions of outcome monitoring systems that cover a large network of programmes are now available $e^{52,53}$.

System-level outcome evaluation also focuses on the functioning of the system, often emphasizing system coordination. Some evaluation strategies are based on general systems theory while others are goaloriented $^{54,55}$. Evaluations that take a general systems theory approach concentrate on such aspects as system integration; the clarity of boundaries with other health and social service systems; the system's capacity to respond to change; the efficiency with which people move into, through and out of the system; and the extent of cooperation among participating service providers. Goal-oriented evaluations focus solely on the ability of the system to achieve its stated goals (e.g. harm reduction) and pay less attention to system processes.

\section{ECONOMIC EVALUATION}

Resources for health care, including treatment of substance use disorders, are limited in any community or region, and choices must be made about their use. Devoting resources to one activity may deprive another of the same. The notion of opportunity cost involves making choices about the allocation of resources. Economic evaluations assist policy makers in making these types of decisions. This type of evaluation involves identifying, measuring, valuing and comparing costs and outcomes of alternative interventions. They indicate which options give the best value for the resources expended. Godfrey ${ }^{56}$ and French ${ }^{57}$ provide excellent overviews of different types of economic evaluations and their application to substance abuse services and systems.

Economic evaluations are undertaken with different perspectives in mind. The most common approach represents a societal perspective whereby costs and outcomes to clients, families, and all members of society are considered. Certain policy makers will take a narrower perspective such that not all of the associated costs and consequences are taken into account. For example, government may be concerned only with the overall impact of various options on the budget for substance use treatment. Here, it would be necessary to trace the direct and indirect consequences of the options on a broad range of funded activities. Studies taken from the perspective of the funder may neglect costs and benefits borne by individuals and families. Different perspectives require different economic evaluation techniques. The main differences involve which actions and outcomes are evaluated. There are three broad questions addressed in economic evaluation:

- Is treatment worthwhile?

- Should investment (or further investment) be made in treatment $A$ or treatment $B$ ?

- Should substance abuse interventions be chosen over other health or welfare interventions?

\section{Is Treatment Worthwhile?}

The question "Is treatment worthwhile" compares the costs and consequences of a particular treatment or system of treatment against the do-nothing alternative. Because the comparison is broad and the consequences are varied, a common unit of measurement for outcomes is required. This unit of measurement is usually monetary. If the net benefits are greater than the costs, the policy maker would determine that the programme is "worthwhile" from this monetary perspective. Research studies have assessed the economic benefit/ cost of several substance abuse treatment interventions including brief interventions for alcohol abuse ${ }^{58}$, drug abuse treatment ${ }^{59}$ and alcoholism treatment ${ }^{60}$. Some studies look at the "cost offset" of substance abuse treatment by examining for example, the cost savings in health care utilization following treatment and comparing these savings to the cost of the treatment ${ }^{61}$.

Should investment (or further investment) be made in treatment $A$ or treatment $B$ ?

For simplicity sake, this question is 
expressed as a choice between two options, but more complex choices or different patterns of service provision can also be addressed. It is important to consider the incremental or marginal position - what are the costs and benefits associated with a small change in the level of each alternative. These marginal cost and benefit comparisons may change between the alternatives depending on the level of activity. Answers to these types of questions involve comparisons across services targeted at with similar outcomes, for example, observed change in the frequency and/or quantity of use of a substance. This would result in a comparison of the costs across two programme alternatives for achieving a given level of outcome. The cost-effectiveness of different programmes can be compared on this basis. The major assumption is that the outcome measure chosen is an adequate representation of programme outcomes. Several costeffectiveness studies of substance abuse treatment have been published $\mathrm{n}$ the research literature $62,63,64,65,66$.

Should substance abuse interventions be chosen over other health or social interventions?

Answering this type of question generally involves comparing programmes having different outcomes and different population groups, for example substance abuse treatment compared to the treatment of diabetes or hypertension. This situation makes evaluation of alternatives difficult since there is unlikely to be a common unit of outcome to be compared. Economists, therefore, suggest the use of an outcome measure that reflects human wellbeing. These are sometimes referred to as measures of "utility" or "quality adjusted life years". Most existing measures have been based on changes in health and quality of life, across different types of health care interventions. Few studies of substance use treatment have used such measures because of difficulty in capturing total changes in wellbeing or quality of life. See ${ }^{67}$ for one study applying the methodology to the drug abuse field.

\section{A HEALTHY CULTURE FOR EVALUATION}

Earlier in this report, Figure 1 illustrated a stepped model for the evaluation of treatment services and systems for substance use disorders. Each type of evaluation addresses different evaluation questions and issues.
Although it is important to tailor specific aspects of an evaluation to the information needs of service or system-level managers, staff, and other key decision-makers, evaluation must be seen as more than simply a set of procedures to be applied within this decision-making context. Evaluation also involves an attitude of questioning within current practice about what outcomes are being achieved and at what cost. In a healthy evaluation culture feedback on all aspects of the service or system, including costs and outcomes, is desired even if it may be less positive than anticipated.

A healthy culture for evaluation is one in which feedback loops are woven into the fabric of the treatment service or system. This is not easy to achieve since many people involved with treatment services and systems have an inherent fear of evaluation. This inhibits the development of a healthy culture for internal evaluation and continuous quality improvement. The concern about being judged underlies the fear of evaluation. Managers and staff, for example, may be afraid of an evaluation because they feel they will be evaluated; they may be afraid for their jobs, their reputations and their clients; or they may be afraid that their programme or community network of programmes will be reduced, abandoned, or modified in a way that is unacceptable to them. They may also fear that they will have no control over the evaluation process, the data being collected and how it will be used.

Although programmes are sometimes significantly modified as a result of an evaluation, it is rare for a particular health or social service to be abandoned only on the basis of one evaluation. Some practical strategies that can be incorporated into a treatment service or system to reduce the fear of evaluation include:

- identifying a person or persons to take the lead role for evaluation;

- implementing an internal quality improvement process and build in evaluation as one component, however small in the beginning;

- securing participation of a group of stakeholders, educating them about evaluation and identifying barriers to evaluation that need to be addressed;

- confirming support for improving the ways your organization or treatment system "learns" and adjusts its practice. This may include developing a formal policy for evaluation for your service or treatment system;

- assessing the current procedures for obtaining feedback on programme or system 
operations, costs and outcomes;

- developing an evaluation plan, including a commitment to start small and gain experience over time;

- secure the support of someone with research expertise if this is not readily available in the service or system;

- developing a plan to monitor your own progress in planning and conducting an evaluation and using the results;

- securing approval from senior administrators and, if appropriate the program funders, to proceed in implementing the evaluation plan.

\section{SUMMARY AND CONCLUSION:}

Since the burden of substance use disorders is so high, it is essential that all communities provide an appropriate treatment response for people with substance use disorders. In the past this response was made largely on the basis of personal experience and opinion rather than information from systematic research and evaluation. With resources for treatment becoming increasingly scarce, duplication and inefficiency in the delivery of services can no longer be tolerated. Programme evaluations that help make good decisions about the use of resources for substance use treatment are taking on an increasingly important role.

This article has introduced programme evaluation and different types of evaluation. It builds upon several years of work in this area by the author and his colleagues and culminating in a series of evaluation workbooks published by the World Health Organization ${ }^{31,68}$. These workbooks provide practical tips and tools for undertaking evaluation of substance abuse treatment services in very user-friendly format. This article and the complementary WHO workbooks are intended to enhance the capacity of programme planners, managers, staff and other decision makers for carrying out evaluation activities. The broader goal of this resource material is to enhance treatment efficiency and cost-effectiveness through the use of the information that comes from these evaluation activities.

It is important that the process of planning for programme evaluation, and the implementation of the various evaluation strategies, be viewed as a learning process for all the people involved. Not everyone has the same enthusiasm for evaluation, especially when trade-offs must be made between resources for programme evaluation and resources for direct service delivery. However, the delivery of high quality treatment services depends critically on feedback about emerging community needs as well as programme operations, outcomes and costs. Such feedback must play a more important role in the way decisions are made and resources are allocated for the treatment of substance use disorders.

\section{REFERENCES}

1. Miller, W.R., Walters, S.T., \& Bennett, M.E. (2000). How effective is alcoholism treatment in the United States? Journal of Studies on Alcohol, 62, 211-220.

2. Prendergast, M.L., Podus, D., Chang, E., \& Urada, D. (2002). The effectiveness of drug abuse treatment: a meta-analysis of comparison group studies. Drug and Alcohol Dependence, 67, 53-72.

3. Anderson, P. (2003). The risk of alcohol. What general practice can do. Nijmegen, Netherlands: Drukkerij Quickprint.

4. World Health Organization (1993). Approaches to treatment of substance abuse (WHO/PSA/93.10). World Health Organization: Geneva.

5. Berlin, S.B. (1989). Single-case evaluation: Another version (Reading 15-1). In Compton, B.R., \& Galaway, B. (Eds.) Social work processes, 4th Ed., Belmont, Cal.: Wadsworth, pp.658-690.

6. Hudson, J., \& Grinnell, R.M. (1989). Evaluation. (Chapter 15). In Compton, B.R., \& Galaway, B. (Eds.), Social work processes, $4^{\text {th }}$ Ed., Belmont, Cal.:Wadsworth, pp.658678.

7. Hargreaves, W.A., Catalano, R.A., Hu, T.W., \& Cuffel, B. (1998). Mental health services research. In: Bellack, A.S., Hersen, M., (Eds.) Comprehensive clinical psychology. New York, NY: Pergamon, 225-241.

8. Randolph, F., Blasinsky, M., Leginski, W., Buckley Parker, L., \& Goldman, H.H. (1997). Creating integrated service systems for homeless persons with mental illness: The ACCESS program. Psychiatric Services, 48(3), 369-373.

9. Morrissey, J., Calloway, M., Johnsen, M., \& Ullman, M. (1997). Service system performance and integration: A baseline profile of the ACCESS demonstration sites. Psychiatric Services, 48(3), 374-380.

10. Rossi, P.H., \& Freeman, H.E. (1982). Evaluation: A systematic approach ( $2^{\text {nd }}$ Ed.) Beverly Hills, Ca.: Sage Publications.

11. Leebow, W., \& Ersoz, C.J. (1991). The health care manager's guide to continuous quality improvement. American Hospital Publishing Inc.

12. Preskill, H., \& Torri, R.T. (1999). Evaluative inquiring for learning in organizations. Thousand Oaks, CA: Sage.

13. Love, A.W., (1993). Internal evaluation: An essential tool for human service organizations. The Canadian Journal of Program Evaluation, 8(2), 1-15.

14. Hudson, J., Mayne, J., \& Thomlison, R., eds. (1992) Action-oriented evaluation in organizations: Canadian practices. Toronto, ON: Wall \& Emerson, Inc.

15. Lewin, K. (1946). Action research and minority problems. Journal of Social Issues, 2, 24-46.

16. Nelson, G., Lord, J., \& Ochocka, J. (2001). Shifting the paradigm in community mental health towards empowerment and community. Toronto, ON: University of Toronto Press.

17. Eddy, D.M. (1998). Performance measurement: Proble- 
ms and solutions. Health Affairs, 17, 7-24.

18. Newcomer, K.E. (1997). Using performance measurement to improve programs. In: Newcomers, K.E. (Eds.) Using performance measurement systems to improve public and non profit programs. San Francisco, CA: Jossey-Bass, 5-13.

19. Rosenheck, R., \& Cicchetti, D. (1998). A mental health program report card: A multidimensional approach to performance monitoring in public sector programs. Community Mental Health Journal, 34, 85-106.

20. Dennis, L.M., Perl, H.I., Huelmer, R.B., et al. (2000). Twenty-five strategies for improving the design, implementation and analysis of health service research related to alcohol and other drug abuse treatment. Addiction, 95(Supplement 3), S281-S308.

21. Ogborne, A.C., Braun, K., \& Rush, B.R. (1998). Developing an integrated information system for specialized addiction treatment agencies. The Journal of Behavioural Health Services and Research, 2511, 100-107.

22. Maddock, J.M., Daley, D., \& Moss, H.B. (1988). Needs assessment techniques: A practical approach to needs assessment for chemical dependency programs. Journal of Substance Abuse Treatment, $\underline{5}, 105-11$.

23. Rush, B.R. (1990). Systems approach to estimating the required capacity of alcohol treatment services. British Journal of Addiction, 85(1), 49-59.

24. Dewit, D.J., \& Rush, BR. (1996). Assessing the need for substance abuse services: A critical review of needs assessment models. Evaluation and Program Planning, $\underline{19}(1), 41-64$

25. Posavac, E.J., \& Carey, R.G. (1997). Program evaluation: Methods and case studies. $5^{\text {th }}$ Edition. Upper Saddle River, NJ: Prentice Hall.

26. Rutman, L. Evaluability assessment. Program analysis In Rutman L. (Ed.) Planning useful evaluation. Evaluability assessment. Beverly Hill, CA: Sage, 1977.

27. Rush, B.R., \& Ogborne, A.C. (1991). Program logic models: Expanding their role and structure. Canadian Journal of Program Evaluation, 6, 93-105.

28. Chan, H.T. (1994). Theory-driven evaluation: Need, difficulties and options. Evaluation Practice, 15, 79-82.

29. Mercer, S.L., \& Goel, V. (1994). Program evaluation in the absence of goals: A comprehensive approach to the evaluation of a population-based breast cancer screening program. The Canadian Journal of Program Evaluation, 9, 97-112.

30. Julian, D.A., Jones, A., \& Deyo, D. (1995). Open systems evaluation and the logic model: Program planning and evaluation tools. Evaluation and Program Planning, 18(4), 333-341.

31. Marsden, J., Ogborne, A., Farrell, M., et al. (2000) International guidelines for the evaluation of treatment services and systems for psychoactive substance use disorders. Geneva, Switzerland: World Health Organization.

32. Wong Rieger, D., \& David, L. (1995). Using program logic models to plan and evaluate education and prevention programs. In: Love A.J., ed. Evaluation methods sourcebook II. Ottawa: Canadian Evaluation Society.

33. Poole, D.L., Nelson, J., Carnaham, S., et al. (2000). Evaluating performance measurement systems in nonprofit agencies: The Program Accountability Scale. American Journal of Evaluation, 21, 15-26.

34. McLellan, A.T., Alterman, A.I., Cacciola, J. et al. (1992). A new measure of substance abuse treatment: Initia studies of the Treatment Services Review. Journal of Nervous and Mental Disease 180, 101-110.

35. Single, E., Robson, L., Xie, X., \& Rehm, J. (1998). The economic costs of alcohol, tobacco and illicit drugs in Canada, 1992. Addiction, 93(7), 991-1006

36. Single, E. (1995). Report of the Second International Symposium on the Economic and Social Costs of Subs- tance Abuse, October 2-5, 1995. Ottawa, Can.: Canadian Centre on Substance Abuse.

37. French, M.T., Dunlap, L.J., Zarkin, G.A., McGeary, K.A., \& McLellan, A.T., (1996). A structured instrument for estimating the economic cost of drug abuse treatment. Journal of Substance Abuse Treatment, 14(4), 1-11.

38. Yates, B.T. Analysing costs, procedures, processes and outcomes in human services. Thousand Oaks, CA: Sage; 1996.

39. French, M.T., Sacks, S., De Leon, G., Staines, G., \& McKendrick, K., (1999). Modified therapeutic community for mentally ill chemical abusers: Outcomes and costs. Evaluation \& the Health Professions, 22(1), 60-85.

40. French, M.T., Bradley, C.J., Calingaert, B., Dennis, M., \& Karuntzos, G.T. (1994). Cost analysis of training and employment services in methadone treatment. Evaluation and Program Planning, 17(2), 107-120.

41. Cisler, R., Holder, H.D., Longabaugh, R., Stout, R.L., \& Zweben, A. (1998). Actual and estimated replication costs for alcohol treatment modalities: Case study from project MATCH. Journal of Studies on Alcohol, 59, 503-512.

42. Greenfield, T.K., \& Attkisson, C.C. (1989). Steps toward a multifactorial satisfaction scale for primary care and mental health services. Evaluation and Program Planning, 12, 271-278.

43. Attkisson, C.C., \& Greenfield, T.K., (1995). The client satisfaction questionnaire (CSQ) scales and the service satisfaction scale-30 (SSS-30). In Sederer, L.I. \& Dickey, B. (Eds.). Outcomes Assessment in Clinical Practice. Baltimore: Williams \& Wilkins.

44. Leebow, W., \& Scott, G. (1994). Service quality improvement. The customer satisfaction strategy for health care. American Hospital Publishing Inc.

45. Lebow, J.L., (1983). Client satisfaction with mental health treatment. Evaluation Review, 7(6), 729-752.

46. Kolodziej, M.E., Greenfield, S.F., \& Weiss, R.D. (2002). Outcome measurement in substance use disorders. In W.W. Ishak, T. Burt \& L.I. Sederer (Eds.). Outcome measurement in psychiatry. A critical review. Washington, D.C.: American Psychiatric Publishing Inc., pp. 207-220.

47. Rounsaville, B.J., \& Poling, J. (2000). Substance use disorder measures. In Task Force for the Handbook of Psychiatric Measures (Eds.) Handbook of psychiatric measures. Washington, D.C., American Psychiatric Association, pp. 457-484

48. Addiction Research Foundation (1993). Directory of client outcome measures for addiction treatment programs. Toronto: Addiction Research Foundation.

49. Dennis, M.L. (1999). Integrating research and clinical assessment: Measuring client and program needs and outcomes in a changing service environment. NIDA Resource Centre for Health Services Research. (www.nida.nih.gov)

50. The WHOQOL Group (1995). The World Health Organization Quality of Life Assessment (WHOQOL): Position paper from the World Health Organization. Social Science and Medicine, 41(10), 1403-1409.

51. McLellan, A.T., Woody, G., \& Metzger, D. et al. (1996). Evaluating the effectiveness of addiction treatments: Reasonable expectations, appropriate comparisons. The Millbank Quarterly, 74(1), 51-85.

52. Gossop, M., Marsden, J., Stewart, D. Lehmann, $P$. Edwards, C., Wilson, A., \& Segar, G. (1998). Substance use, health and social problems of service users at 54 treatment agencies. British Journal of Psychiatry, 173, 166-171.

53. Harrison, P.A., Beebe, T.J., Fulkerson, J.A., \& Torgerud, C.R. (1996). The development of patient profiles for Minnesota's treatment outcomes monitoring system, Addiction, 91(5), 687-700.

54. Strausser, S., Eveland, J.D., Cummins, G., Deniston, 
O.L., \& Romani, J.H. (1981). Conceptualizing the goal and systems models of organizational effectiveness implications for comparative evaluation research. Journal of Management Studies, 18, 321-340.

55. Julian, D.A. (1997). The utilization of the logic model as a system level planning and evaluation device. Evaluation and Program Planning, 20(3), 251-257.

56. Godfrey, C. (1994). Assessing the cost-effectiveness of alcohol services. Journal of Mental Health, $\underline{3}$, 3-21.

57. French, M.T., (1995). Economic evaluation of drug abuse treatment programs: Methodology and findings. American Journal of Drug Alcohol Abuse, 21(1), 111-135.

58. Fleming, M.F., Mundt, M.P., French, M.T., Manwell, L.B., Stauffacher, B.A., \& Barry, K.L. (2000). Benefit-cost analysis of brief physician advice with problem drinkers in primary care settings. Medical Care, 38(1), 7-18.

59. Hubbard, R.T., \& French, M. (1991). New perspectives on the benefit-cost and cost-effectiveness of drug abuse treatment. In Cartwright, W.S. \& Kaple, J.M. (Eds.) Economic costs, cost-effectiveness, financing and community-based drug treatment. (Research Monograph 113). Rockville, MD: National Institute on Drug Abuse.

60. Holden, H.D., Cisler, R., Longabaugh, R., Stout, R.L., Treno, A.J., \& Zweben, A. (2000). Alcoholism treatment and health care: A cost-benefit analysis from Project MATCH. Addiction, 95(7), 999-1013.

61. Holden, H.H., \& Blasé, J.O. (1992). The reduction of health care costs associated with alcoholism treatment: A 14-year longitudinal study. Journal of Studies on Alcohol, 53(4), 293-302.

62. Jerrell, J.W., Hu, T., \& Ridgely, M.S. (1994) Cost-effectiveness of substance disorder interventions for people with severe mental illness. The Journal of Mental Health Administration, 21(3), 283-297.

63. Kraft, M.K., Rothbard, A.B., Hadley, T.R., McLellan, T., \& Asch, D.A. (1997). Are supplementary services provided during methadone maintenance really cost effective? American Journal of Psychiatry, 154(9), 1214-1219.

64. Longabaugh, R.L., McCrady, B., Fink, E., Stout, R. McAuley, T., Doyle, C., \&McNeill, D. (1983). Cost-effectiveness of alcoholism treatment in partial vs. inpatient settings. Journal of Studies on Alcohol, 44, 1049-1071.

65. Weisner, C., Mertens, J., Parthasarathy, S., Moore, C., \& $\mathrm{Lu}, \mathrm{Y}$. (2001). Integrating primary medical care with addiction treatment. A randomised controlled trial. Journal of the American Medical Association, 286(14). 1715-1723.

66. Weisner, C., Mertens, J., Parthasaraty, S., Moore, C. Hunkeler, E.M., Hu, T., \& Selby, J. (2000). The outcome and cost of alcohol and drug treatment in an HMO: Day hospital versus traditional outpatient regimens. Health Services Research, 35(4), 791-812,

67. French, M.T., Mauskopf, J.A., Teague, J.L., \& Roland, E.J. (1996). Estimating the dollar value of health outcomes fro drug-abuse interventions. Medical Care, 34(9), 890-910.

68. World Health Organization (2000). Evaluation of substance abuse treatment - Workbook Series. Geneva: World Health Organization.

\section{ABSTRACT}

Scientific research and program evaluation have not played a major role in shaping the development of treatment services and systems in most countries. This has led to disparities in the development, management and monitoring of national treatment systems. In the evaluation of treatment for substance use disorders, the evaluation practitioner will usually activity, treatment service, treatment agency or treatment system. One of the major barriers to undertaking internal program evaluation is the belief that it is a complicated research process best left to those with specific research training. Program managers and staff can plan and initiate an evaluation process for their program if they have access to research expertise when needed for certain parts of the process. There are seven main components of an evaluation process that can be planned and implemented: need assessment; evaluation planning, process evaluation, cost analysis, client satisfaction evaluation, outcome evaluation and economic evaluation. However, evaluation is more than the techniques and technology required to implement these types of activities. It also involves the routine questioning of current practice even if the feedback may be less positive than anticipated. A healthy culture for evaluation is one in which feedback loops are woven into the fabric of the treatment service or system. There are many barriers to evaluation in substance abuse services but these barriers can be overcome with careful planning and commitment to the delivery of evidence-based services.

Key-words: Program evaluation, treatment services, substance use disorders, cost analysis, client satisfaction evaluation, outcome evaluation, economic evaluation.

\section{RESUMO}

A pesquisa científica e a avaliação de programas não têm merecido um papel de destaque no desenvolvimento de serviços e sistemas de tratamento na maioria dos países. Essa lacuna conduziu à disparidades no desenvolvimento, gerenciamento e monitoramento dos sistemas de tratamento em nível nacional. Na avaliação do tratamento para o uso de substâncias, o clínico avaliador estará, geralmente, trabalhando em um dos seguintes níveis: um caso individual, a atividade de tratamento, o serviço de tratamento, o órgão de tratamento ou o sistema de tratamento. Um dos maiores obstáculos para levar a cabo programas internos de avaliação é a crença de que se trata de um complicado processo de pesquisa, que deve ser deixado àqueles que possuam treinamento específico em pesquisa. Os gerentes de programas e as equipes estão aptos a planejar e iniciar um processo de avaliação para seus programas, bastando que tenham acesso a especialistas em pesquisa quando isso se mostrar necessário em partes específicas do processo. Existem sete componentes principais de um processo de avaliação, que podem ser planejados e implementados: avaliação da necessidade, planejamento da avaliação, avaliação do processo, análise de custo, avaliação da satisfação do cliente, avaliação do resultado e avaliação econômica. Entretanto, a avaliação representa mais do que as técnicas e a tecnologia exigidas para a implementação dessas atividades. Ela também 
envolve o questionamento rotineiro da prática utilizada, mesmo quando o feedback possa ser menos positivo que o esperado. Uma cultura saudável de avaliação é aquela na qual os laços de feedback estão entremeados no tecido do serviço ou sistema de tratamento. Existem diversos obstáculos à avaliação em serviços para abuso de substâncias, mas eles podem ser superados através de um criterioso planejamento e do comprometimento com a criação de serviços baseados em evidências.

Descritores: avaliação de programas, sistemas de tratamento, abuso de substâncias, análise de custo, avaliação de satisfação, avaliação de resultados, avaliação econômica.

Título: Avaliação de serviços e sistemas de tratamento para o abuso de substâncias psicoativas

\section{RESUMEN}

La pesquisa científica y la avaluación de programas no han merecido un papel de destaque en el desarrollo de servicios y sistemas de tratamiento en la mayoría de los países. Esta laguna llevó a las disparidades en el desarrollo, gestión y acompañamiento de los sistemas de tratamiento en el ámbito nacional.

En la avaluación del tratamiento para el uso de sustancias, el clínico avaluador estará, generalmente, trabajando en uno de los siguientes niveles: un caso individual, la actividad de tratamiento, el servicio de tratamiento, el órgano de tratamiento o el sistema de tratamiento. Uno de los mayores obstáculos para llevar a cabo programas internos de avaluación es la creencia de que se trata de un complicado proceso de pesquisa, que debe ser dejado a aquellos que poseen entrenamiento específico en pesquisa.

Los gerentes de programas y los equipos están aptos a planear e iniciar un proceso de avaluación para sus programas, bastando que tengan acceso a especialistas en pesquisa cuando eso se muestre necesario en partes específicas del proceso. Existen siete componentes principales de un proceso de avaluación, que pueden ser planeados e implementados: avaluación de la necesidad, planificación de la avaluación, avaluación del proceso, análisis de costo, avaluación de la satisfacción del cliente, avaluación del resultado y avaluación económica. Sin embargo, la avaluación representa mas que las técnicas y la tecnología exigidas para la implementación de esas actividades. Ella también envuelve el cuestionario rutinero de la práctica utilizada, mismo cuando el feedback pueda ser menos positivo que lo esperado.

Una cultura saludable de avaluación es aquella en la cual los lazos de feedback están entrelazados en el tejido del servicio o sistema de tratamiento. Existen diversos obstáculos a la avaluación en servicios para abuso de sustancias, pero ellos pueden ser superados a través de una cuidadosa planificación y del comportamiento con la creación de servicios basados en evidencias.

Palavras-clave: Avaluación de programas, sistemas de tratamiento, abuso de sustancias, análisis de costo, avaluación de satisfacción, avaluación de resultados, avaluación económica.

Título: Avaluación de servicios y sistemas de tratamiento para el abuso de sustancias psicoactivas

Endereço para correspondência:

Brian Rush

Health Systems Research and Consulting Unit

Centre for Addiction and Mental Health

Toronto, Ontario

E-mail: brian_rush@camh.net

Copyright (c) Revista de Psiquiatria do Rio Grande do Sul - SPRS 